Check for updates

Cite this: RSC Adv., 2018, 8, 9462

\title{
Structure analysis of precursor alloy and diffusion during dealloying of Ag-Al alloy $\dagger$
}

\author{
Runwei Zhang, ${ }^{a}$ Xu Wang, (DD *a Zhichao Zhang, ${ }^{\text {a }}$ Jacob C. Huang, ${ }^{\mathrm{b}}$ Feng Shi ${ }^{\mathrm{a}}$ \\ and Ming $\mathrm{Wu}^{\mathrm{a}}$
}

Nanoporous silver (NPS) was fabricated by dealloying Ag-Al alloy ribbons with nominal compositions of 30 , 35 and 40 at\% $\mathrm{Ag}$ (corresponding to hypoeutectic composition, eutectic composition and hypereutectic composition, respectively). The microstructures of the Ag-Al precursor and as-dealloyed samples were observed using a scanning electron microscope (SEM) and a transmission electron microscope (TEM) as well as via focused ion beam (FIB) technique. We concluded that with the increase in Ag content from 30 to 40 at\%, the diameter of ligament increased from $70 \pm 15 \mathrm{~nm}$ to $115 \pm 35 \mathrm{~nm}$. Due to the method of crystalline solidification and the distribution of $\alpha$-Al(Ag) and $\gamma-A_{2} A l$ phases, the as-dealloyed $A_{35} A_{65}$ alloy exhibited a homogeneous ligament/pore structure, whereas the microstructures of $\mathrm{Ag}_{30} \mathrm{Al}_{70}$ and $\mathrm{Ag}_{40} \mathrm{Al}_{60}$ showed thinner and coarser ligament structures, respectively.

Received 30th November 2017 Accepted 20th February 2018

DOI: 10.1039/c7ra12915g

rsc.li/rsc-advances

studies on the fabrication of nanoporous metals have not

\section{Introduction}

Nanoporous metals have recently attracted considerable attention in many applications such as catalysis, optics, sensors, actuators and energy storage because of their special structures and properties. ${ }^{1-4}$ In addition, nanoporous metals exhibit a three-dimensional (3D), bi-continuous ligament/pore structures. Recently, nanoporous metals have been commonly fabricated by template and dealloying methods, which include the replication of porous templates and the removal of one or more active metal elements from an alloy, respectively. ${ }^{5-10}$

Compared with the template method, the dealloying method is more flexible in modulating the microstructure as well as the size of the ligament/pore structure. Furthermore, the dealloying processes and microstructures of nanoporous metals are affected by many factors such as precursor alloy composition and dealloying solution, ${ }^{11}$ temperature ${ }^{12}$ and time. ${ }^{13}$ Therefore, investigating the dealloying process and the formation mechanism of nanoporous metals is essential.

In recent years, an increasing number of studies have been conducted to explore the fabrication of nanoporous metals by dealloying. Correspondingly, many nanoporous metals have been fabricated through dealloying from binary or ternary alloy systems, such as $\mathrm{Cu}-\mathrm{Pt},{ }^{14} \mathrm{Ag}-\mathrm{Au},{ }^{15} \mathrm{Cu}-\mathrm{Au}^{16}$ and $\mathrm{Au}-\mathrm{Ag}-\mathrm{Pt},{ }^{17}$ most of those binary or ternary alloy systems possess singlephase solid solubility across all compositions. However,

${ }^{a}$ School of Mechanical Engineering, Liaoning Shihua University, Fushun 113001, P. R. China.E-mail: wangxu@lnpu.edu.cn;wx1979875@hotmail.com

${ }^{b}$ Institute for Advanced Study, Department of Materials Science \& Engineering, City University of Hong Kong, Kowloon, Hong Kong

$\dagger$ Electronic supplementary information (ESI) available. See DOI: 10.1039/c7ra12915g merely concentrated on the single-phase alloy systems; bi-phase (even multi-phase) alloys or compounds, such as $\mathrm{Ag}-\mathrm{Al},{ }^{18} \mathrm{Al}-$ $\mathrm{Cu},{ }^{19} \mathrm{Mg}-\mathrm{Cu}^{20}$ and $\mathrm{Al}-\mathrm{Ag}-\mathrm{Au},{ }^{21}$ have also been proved to be appropriate for the fabrication of nanoporous metals or composites. Consequently, the mechanical behaviour and the formation mechanism of nanoporous composites and metals during the dealloying process are worthy of investigation. For example, nanoporous $\mathrm{Cu}$ is prepared via chemical dealloying of $\mathrm{Ag}-\mathrm{Cu}$ alloys and the mechanical behaviour of bulk nanoporous $\mathrm{Cu}$ is discussed. ${ }^{22}$ The microstructure and phase evolution during dealloying of the bi-phase $\mathrm{Ag}-\mathrm{Al}$ alloy are reported; the results suggest that the dealloying of $\alpha-\mathrm{Al}(\mathrm{Ag})$ and $\mathrm{Ag}_{2} \mathrm{Al}$ starts simultaneously, and subsequently, the residual $\mathrm{Ag}_{2} \mathrm{Al}$ is dealloyed. ${ }^{23}$

Owing to their economical costs, relatively high strengths and high electrical and thermal conductivities, ${ }^{\mathbf{2 4 , 2 5}} \mathrm{Ag}, \mathrm{Al}$ and $\mathrm{Cu}$ have been used as substitutes for Au. In addition, some dealloying strategies for the preparation of nanoporous $\mathrm{Ag}$ dealloyed from $\mathrm{Ag}-\mathrm{Al}^{26}$ and $\mathrm{Ag}-\mathrm{Cu}$ alloys have been reported. ${ }^{27,28}$ However, the dealloying behaviour and microstructure evolution of the initial $\mathrm{Ag}$ alloys still needs to be explained in detail. Compared with the single-phase $\mathrm{Au}-\mathrm{Ag}$ binary alloy system, binary alloy systems with more than one phase, such as $\mathrm{Ag}-\mathrm{Al}$ and $\mathrm{Ag}-\mathrm{Cu}$ alloys, complicate the dealloying process and microstructural evolution. Therefore, further research on dealloying $\mathrm{Ag}, \mathrm{Al}$ and $\mathrm{Cu}$ is needed.

In addition, the effects of the alloy composition on microstructures (especially the ligament/pore size) of the resulting nanoporous structures were investigated. ${ }^{29,30}$ However, detailed studies on the effect of phase formation and distribution on the microstructure of nanoporous silver (NPS) are relatively few. Therefore, in this study, we designed and prepared $\mathrm{Ag}-\mathrm{Al}$ 
precursor alloys with different compositions based on $\mathrm{Ag}-\mathrm{Al}$ phase diagrams. From the $\mathrm{Ag}-\mathrm{Al}$ phase diagram, ${ }^{31}$ the eutectic point was found to be 67 at $\%$ for $\mathrm{Al}$ at $840 \mathrm{~K}\left(567^{\circ} \mathrm{C}\right)$. Thus, the $\mathrm{Ag}$ contents in $\mathrm{Ag}_{30} \mathrm{Al}_{70}, \mathrm{Ag}_{35} \mathrm{Al}_{65}$ and $\mathrm{Ag}_{40} \mathrm{Al}_{60}$ corresponded to hypoeutectic, eutectic, and hypereutectic compositions, respectively. Moreover, we briefly discussed the phase distribution involving halo formation during the solidification process of alloys. Halo formation means that one phase is formed around another phase that was formed initially. ${ }^{32}$ This process commonly occurs during the solidification of offeutectic alloys.

\section{Materials and methods}

The Ag-Al precursor alloys with Ag compositions of 30, 35 and 40 at\% were prepared by melting pure metals ( $\mathrm{Al}$ and $\mathrm{Ag}$ in $99.9 \mathrm{wt} \%$ purity) in a high-frequency induction melting furnace. The alloy was heated to a temperature that was $100{ }^{\circ} \mathrm{C}$ above the melting point of the alloy and was kept for 10-20 minutes. The $\mathrm{Ag}-\mathrm{Al}$ alloy ingot was then re-melted and was rapidly solidified into ribbons (thickness: 40-60 $\mu \mathrm{m}$; width: $\sim 10 \mathrm{~mm}$ ) via singleroller melt-spinning with copper mould water cooling plant (cooling rate: $50-300{ }^{\circ} \mathrm{C} \mathrm{s}^{-1}$; rotational speed: 2500 revolutions per minute). The Ag-Al alloy samples are depicted in Fig. 1. The melt-spun $\mathrm{Ag}-\mathrm{Al}$ ribbons were dealloyed by immersing them in $200 \mathrm{ml}, 5 \mathrm{wt} \%$ dilute hydrochloric acid $(\mathrm{HCl})$ at $60{ }^{\circ} \mathrm{C}(333 \mathrm{~K})$. To observe the dealloying behaviour of the $\mathrm{Ag}-\mathrm{Al}$ alloy during the dealloying process, Ag-Al ribbons were etched for 0, 5, 10, 20 and $30 \mathrm{~min}$. The dealloyed specimens were sequentially rinsed several times with distilled water and ethyl alcohol.

The phase patterns of precursor alloys and as-dealloyed samples were collected using an X-ray diffractometer (XRD) with a scanning speed set at $2^{\circ} \mathrm{min}^{-1} .2 \theta$ scans were performed between $20^{\circ}$ and $90^{\circ}$. The microstructures of the $\mathrm{Ag}-\mathrm{Al}$ precursor and the as-dealloyed samples were observed using a Hitachi SU8000 scanning electron microscope (SEM) and an FEI Tecnai G2 F20 transmission electron microscope (TEM) via a focused ion beam (FIB) apparatus (Seiko SMI3050). The ligament sizes of nanoporous Ag in SEM images were measured by a Java-based public image processing software imageJ. The content of $\mathrm{Al}$ and $\mathrm{Ag}$ in the precursor and the as-dealloyed samples was detected through an energy dispersive X-ray spectroscopy (EDS) analyser attached to SEM.

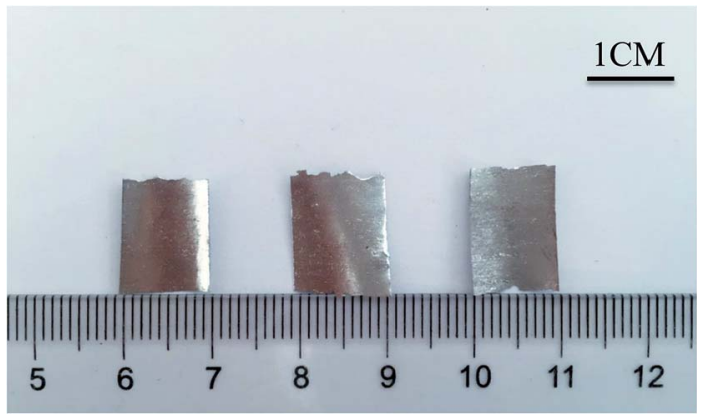

Fig. 1 Photograph of the $\mathrm{Ag}-\mathrm{Al}$ alloy ribbons.

\section{Results and discussion}

\section{Characterization of melt-spun $\mathbf{A g}-\mathbf{A l}$ precursor alloy}

The SEM micrographs (plan view) of the $\mathrm{Ag}_{30} \mathrm{Al}_{70}, \mathrm{Ag}_{35} \mathrm{Al}_{65}$ and $\mathrm{Ag}_{40} \mathrm{Al}_{60}$ melt-spun samples are shown in Fig. 2, which also shows that distinct grain boundaries (or phase boundaries) appeared in the $\mathrm{Ag}_{30} \mathrm{Al}_{70}$ and $\mathrm{Ag}_{35} \mathrm{Al}_{65}$ as-spun alloys, and the morphology of the $\mathrm{Ag}_{35} \mathrm{Al}_{65}$ precursor alloy was more uniform than that of the $\mathrm{Ag}_{30} \mathrm{Al}_{70}$ alloy. The corresponding EDS results of the Ag-Al precursor alloys are shown in Fig. 2(b), (d) and (f). The results were consistent with our designation of the alloy composition in the initial $\mathrm{Ag}-\mathrm{Al}$ alloys. Fig. 3 shows the XRD patterns of the melt-spun $\mathrm{Ag}-\mathrm{Al}$ ribbons with an $\mathrm{Ag}$ content of 30-40 at\%. The XRD patterns depicted two phases in the meltspun $\mathrm{Ag}-\mathrm{Al}$ alloys, namely, the phases of the $\alpha-\mathrm{Al}(\mathrm{Ag})$ solid solution and $\gamma-\mathrm{Ag}_{2} \mathrm{Al}$ intermetallic compound.

\section{Microstructure of as-dealloyed $\mathrm{Ag}-\mathrm{Al}$ ribbons}

Fig. 4 shows the XRD patterns of the as-dealloyed $\mathrm{Ag}-\mathrm{Al}$ ribbons. According to the $\mathrm{XRD}$ results, the diffraction peaks corresponding to $\alpha-\mathrm{Al}(\mathrm{Ag})$ and $\gamma-\mathrm{Ag}_{2} \mathrm{Al}$ disappeared. In addition, the as-dealloyed ribbons with Ag content ranging from 30 to 40 at $\%$ in the precursor alloys contained only one phase: the single face-centered-cubic (FCC) Ag phase. In addition, the $\alpha$-Al(Ag) and $\mathrm{Ag}_{2} \mathrm{Al}$ phases were completely dealloyed, whereas $\mathrm{Al}$ from these two phases leached out entirely.

Fig. 5 shows the microstructures of the NPS ribbons (plan view) dealloyed from the $\mathrm{Ag}_{30} \mathrm{Al}_{70}$ alloys for different durations in a $5 \mathrm{wt} \% \mathrm{HCl}$ solution at $60{ }^{\circ} \mathrm{C}$. The morphology of the resulting NPS ribbon dealloyed for $30 \mathrm{~min}$ exhibited an inhomogeneous, ligament-channel structure. Moreover, some deep channels (or large cracks) were formed at the early stage of the dealloying process, and they became more uniform as time progressed. After being dealloyed for $30 \mathrm{~min}$, the diameter of the ligament became coarse and changed from $60 \pm 15$ to $72 \pm$ $35 \mathrm{~nm}$. Fig. 5(e) shows the EDS pattern of the $\mathrm{Ag}_{30} \mathrm{Al}_{70}$ alloy dealloyed for $30 \mathrm{~min}$. This indicated that there was no $\mathrm{Al}$ element that could be detected in the as-dealloyed ${ } g_{30} \mathrm{Al}_{70}$ sample.

The microstructures of the NPS ribbons (plan view) dealloyed from the $\mathrm{Ag}_{35} \mathrm{Al}_{65}$ alloys for different durations are shown in Fig. 6. It was obvious that the final porous structure of the resulting NPS ribbon (Fig. 6d) was more homogeneous than those of $\mathrm{Ag}_{30} \mathrm{Al}_{70}$ (Fig. 5d) and $\mathrm{Ag}_{40} \mathrm{Al}_{60}$ (Fig. 7d) alloy ribbons, and it exhibited a bi-continuous, interpenetrating ligament/ pore structure without the appearance of deep channels (or cracks). The phase distribution is shown in Fig. 6(a). After being dealloyed for $30 \mathrm{~min}$, the diameter of ligament became coarse from $40 \pm 15$ to $90 \pm 35 \mathrm{~nm}$. Fig. 6(e) shows the EDS pattern of $\mathrm{Ag}_{35} \mathrm{Al}_{65}$ alloy dealloyed for $30 \mathrm{~min}$. This indicated that there was no $\mathrm{Al}$ element that could be detected in the as-dealloyed $\mathrm{Ag}_{35} \mathrm{Al}_{65}$ sample.

Fig. 7 shows the morphology of the NPS ribbons (plan view) dealloyed from the $\mathrm{Ag}_{40} \mathrm{Al}_{70}$ alloys and a nearly homogeneous interpenetrating ligament-channel structure. The phase distribution is shown in Fig. 7(a). However, the diameter of the 

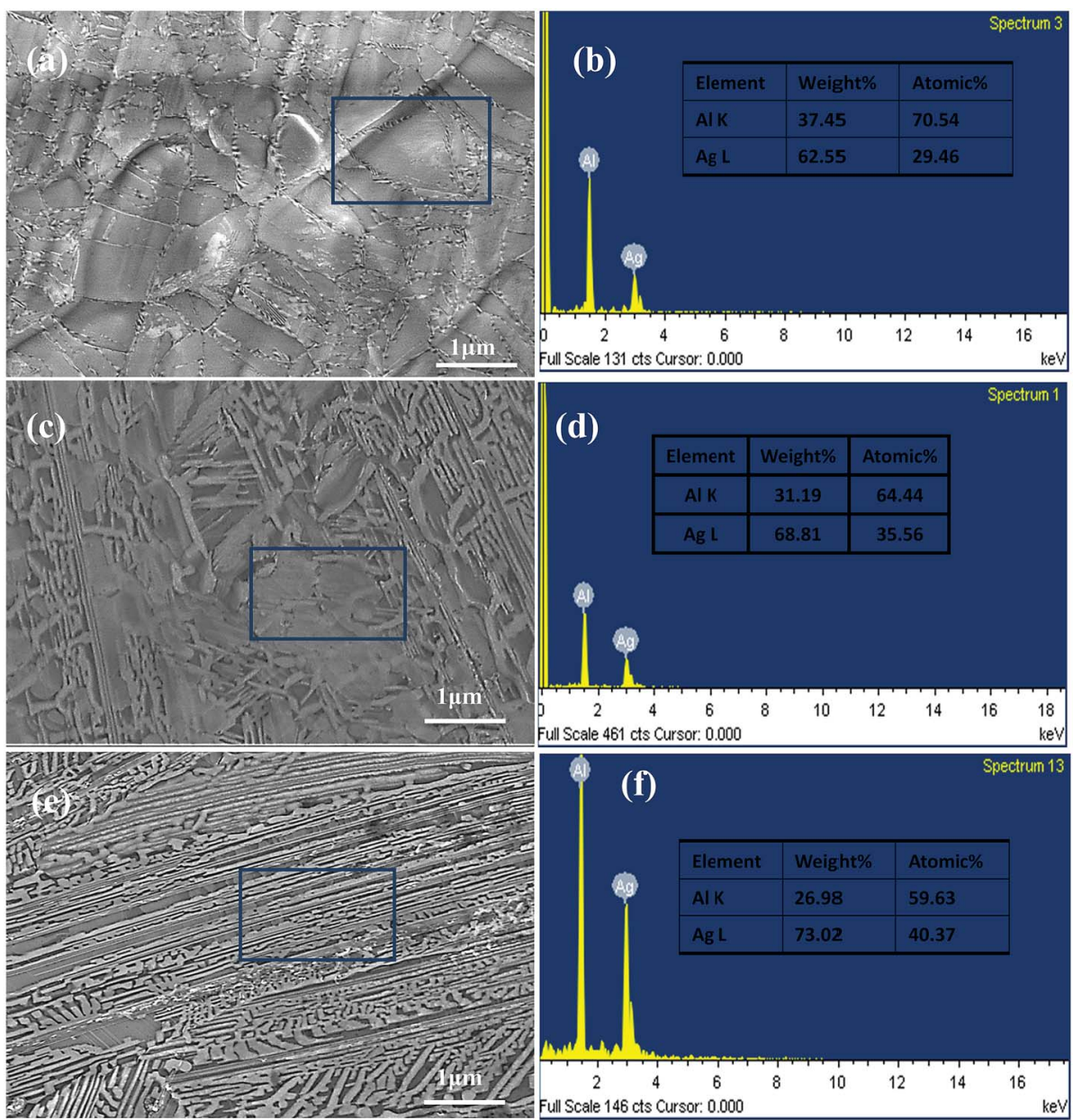

Fig. 2 SEM micrographs of the (a) $\mathrm{Ag}_{30} \mathrm{Al}_{70}$, (c) $\mathrm{Ag}_{35} \mathrm{Al}_{65}$ and (e) $\mathrm{Ag}_{40} \mathrm{Al}_{60}$ melt-spun samples (plan view); (b), (d) and (f) EDS results of $\mathrm{Ag}{ }_{30} \mathrm{Al}$ (70, $\mathrm{Ag}_{35} \mathrm{Al}_{65}$ and $\mathrm{Ag}_{40} \mathrm{Al}_{60}$ precursor alloy samples.

ligament dealloyed for 30 min from the $\mathrm{Ag}_{40} \mathrm{Al}_{70}$ alloy reached approximately $150 \mathrm{~nm}$ and was much larger than those of the $\mathrm{Ag}_{30} \mathrm{Al}$ and $\mathrm{Ag}_{35} \mathrm{Al}$ alloys. This result suggested that the size of the

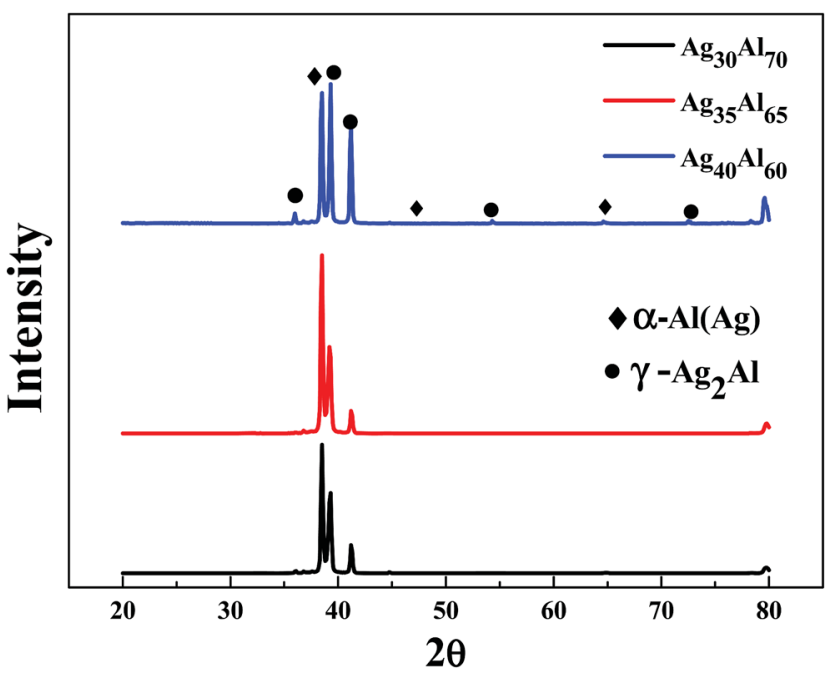

Fig. 3 XRD patterns of the melt-spun Ag-Al ribbons. ligament became larger with the increase in $\mathrm{Ag}$ content. After being dealloyed for $30 \mathrm{~min}$, the diameter of the ligament coarsened from $90 \pm 15$ to $115 \pm 35 \mathrm{~nm}$. Fig. 7(e) shows the EDS pattern of $\mathrm{Ag}_{40} \mathrm{Al}_{60}$ alloy dealloyed for $30 \mathrm{~min}$. This indicated that no $\mathrm{Al}$ element could be detected in the as-dealloyed $\mathrm{Ag}_{40} \mathrm{Al}_{60}$ sample.

From the EDS patterns (Fig. 5e, 6e and 7e) of $\mathrm{Ag}_{30} \mathrm{Al}_{70}$, $\mathrm{Ag}_{35} \mathrm{Al}_{65}$ and $\mathrm{Ag}_{40} \mathrm{Al}_{60}$ alloys, respectively, we concluded that after dealloying, there was no residual $\mathrm{Al}$ element in the $\mathrm{Ag}-\mathrm{Al}$ alloy samples. Thus, the EDS patterns were consistent with the XRD results (Fig. 4). However, it is unreasonable to say that there was absolutely no Al left. Moreover, because the amount of residual $\mathrm{Al}$ was too small, it could be ignored. ${ }^{18}$

\section{Diffusion of $\mathrm{Ag}$ atoms during the dealloying process}

The micro-scale changes in ligaments and pores during the dealloying process are shown in Fig. 8. To clearly understand the formation mechanism of the nanoporous structure, the dependence of the growth kinetics of ligament on the diffusion of $\mathrm{Ag}$ was investigated. The analysis of the statistical data suggested that the coarsening of the ligament and the pores followed a nonlinear relationship, and the ligament sizes increased with an increase in Ag contents. Moreover, consistent 


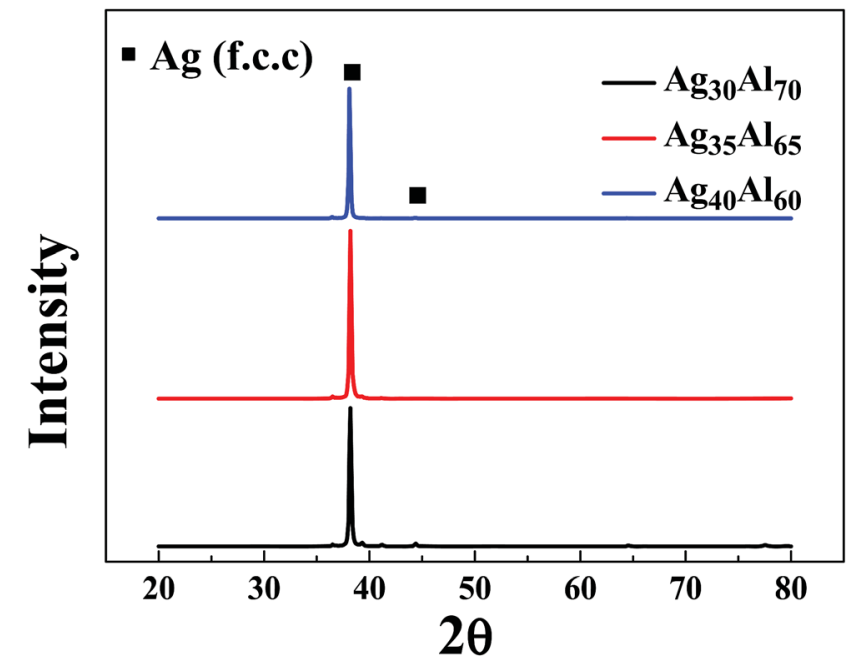

Fig. 4 XRD patterns of $\mathrm{Ag}-\mathrm{Al}$ samples under the dealloyed condition for $30 \mathrm{~min}$. with the observations in the SEM results, the ligament size of the $\mathrm{Ag}_{35} \mathrm{Al}_{65}$ alloy was found to be dimensionally similar to the nanopore size, whereas there were large differences between the ligament and nanopore sizes in $\mathrm{Ag}_{30} \mathrm{Al}_{70}$ and $\mathrm{Ag}_{40} \mathrm{Al}_{60}$.

As reported, the surface diffusion, $D_{\mathrm{s}}$, which is the main factor of the coarsening mechanism, can be estimated by the following equation:

$$
D_{\mathrm{s}}=\frac{[d(t)]^{4} k T}{32 \gamma t \alpha^{4}}
$$

here, $d$ is the diameter of the ligament at time $t, \gamma$ is the surface energy of $\mathrm{Ag}\left(1.24 \mathrm{~J} \mathrm{~m}^{-2}\right),{ }^{33} \alpha$ is the lattice parameter of $\mathrm{Ag}$ $(0.4088 \mathrm{~nm}), D_{\mathrm{s}}$ is the coefficient of surface diffusion of $\mathrm{Ag}, k$ is the Boltzmann constant $\left(1.380648 \times 10^{-23} \mathrm{~J} \mathrm{~K}^{-1}\right)$ and $T$ is the dealloying temperature. Thus, the surface diffusivity results of $\mathrm{Ag}_{30} \mathrm{Al}_{70}, \mathrm{Ag}_{35} \mathrm{Al}_{65}$ and $\mathrm{Ag}_{40} \mathrm{Al}_{60}$ were estimated to be $6.2 \times 10^{-17}$ $\mathrm{m}^{2} \mathrm{~s}^{-1}, 1.5 \times 10^{-16} \mathrm{~m}^{2} \mathrm{~s}^{-1}$ and $4.0 \times 10^{-16} \mathrm{~m}^{2} \mathrm{~s}^{-1}$, respectively. Therefore, slight changes in the alloy composition significantly affected the diffusivity of $\mathrm{Ag}$, and the results from this equation
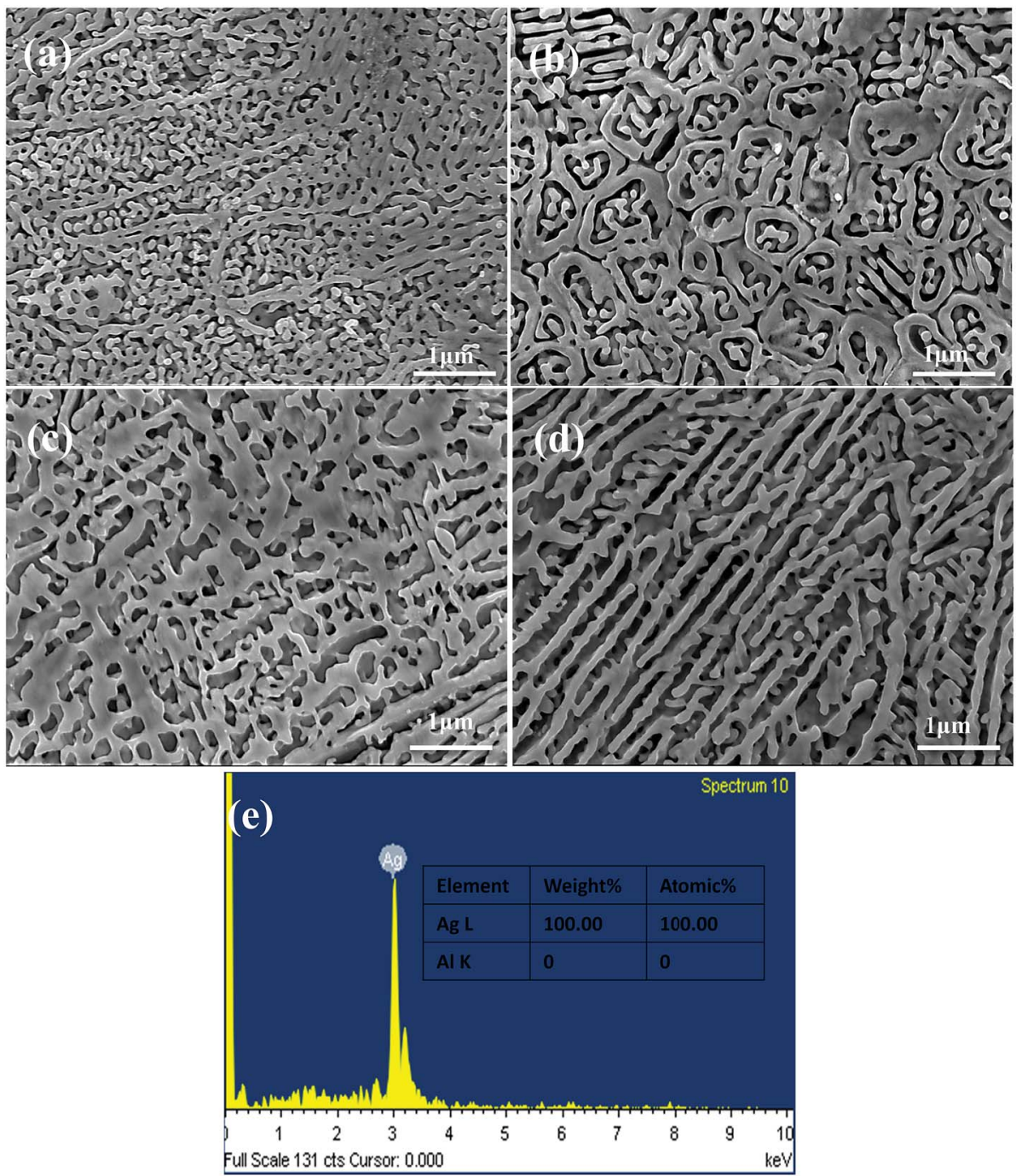

Fig. 5 SEM micrographs of the $\mathrm{Ag}_{30} \mathrm{Al}_{70}$ samples (plan view) under the dealloyed conditions for different periods of time: (a) 5 min, (b) 10 min, (c) $20 \mathrm{~min}$, and (d) $30 \mathrm{~min}$; (e) EDS pattern of $\mathrm{Ag}_{30} \mathrm{Al}_{70}$ sample dealloyed for $30 \mathrm{~min}$. 


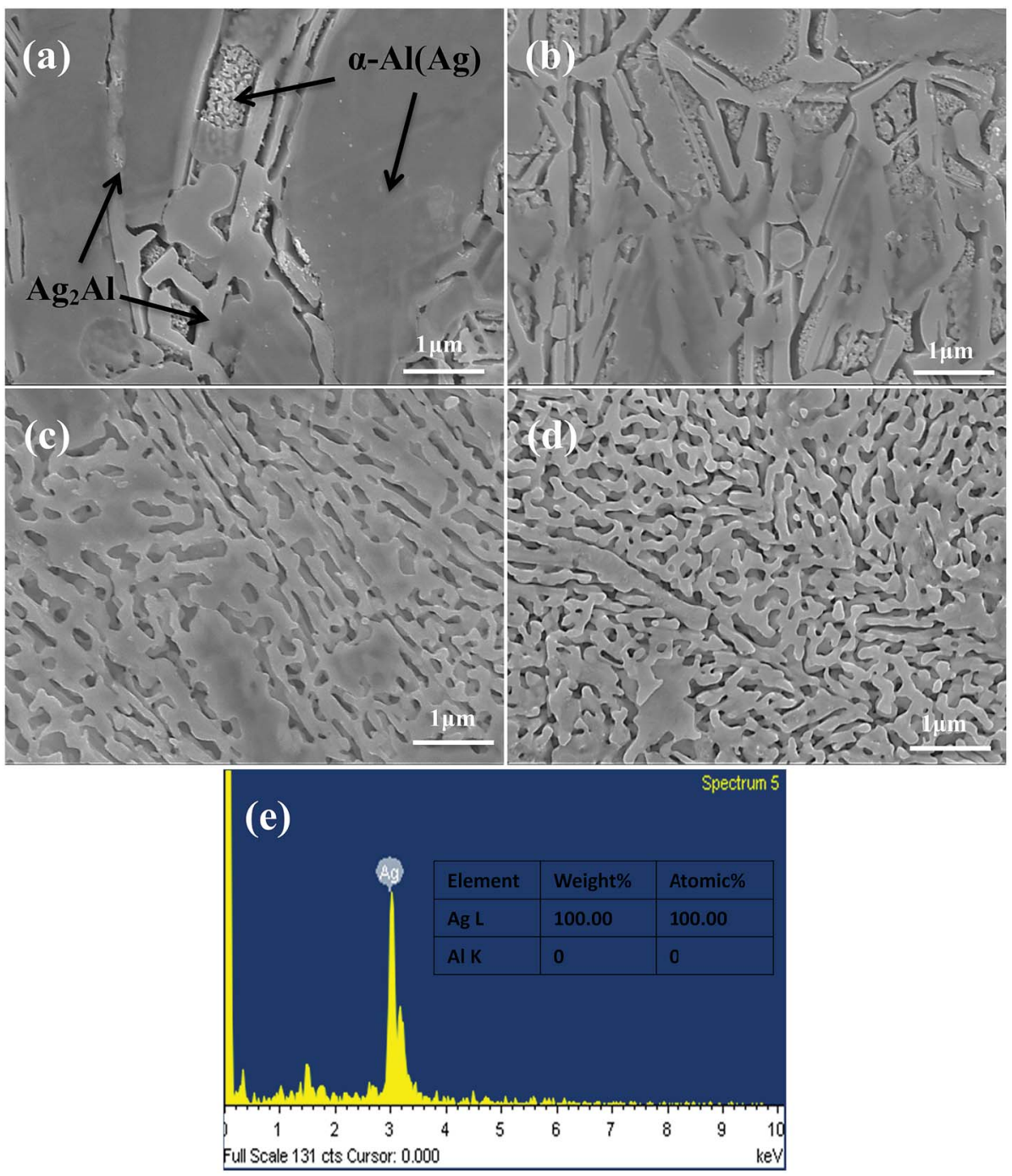

Fig. 6 SEM micrographs of the $\mathrm{Ag}_{35} \mathrm{Al}_{65}$ samples (plan view) under the dealloyed conditions for different periods of time: (a) 5 min, (b) 10 min, (c) $20 \mathrm{~min}$, and (d) $30 \mathrm{~min}$; (e) EDS pattern of $\mathrm{Ag}_{35} \mathrm{Al}_{65}$ sample dealloyed for $30 \mathrm{~min}$.

explained the coarsening behaviour of the Au nanostructure during dealloying. ${ }^{34}$

Fig. 9 shows the bright field TEM image with the inset corresponding to the elected-area diffraction (SEAD) pattern of the $\mathrm{Ag}_{35} \mathrm{Al}_{65}$ alloy. Fig. 9(a) revealed that the ligament comprised polycrystalline $\mathrm{Ag}$ nanoparticles. The distinct morphology exhibited a characteristic ligament/pore structure and was consistent with the SEM observation (Fig. 6). The selected area electron diffraction (SEAD) pattern comprised polycrystalline rings, corresponding to the ( $\left(\begin{array}{lll}\overline{2} & \overline{1} & 1\end{array}\right),\left(\begin{array}{lll}\overline{2} & 0 & 0\end{array}\right)$ and $\left(\begin{array}{lll}\overline{1} & 1 & \overline{1}\end{array}\right)$ planes of FCC Ag. The high-resolution transmission electron microscope (HRTEM) image (Fig. 9b) was taken from Fig. 9(a) and marked by a rectangle. The lattice fringe of the ligament could be clearly observed in the HRTEM image (Fig. 9b), and the inter-planar distance was estimated to be $0.2334 \mathrm{~nm}$, which was in good agreement with that of the $\{111\}$ planes of $\mathrm{Ag}$, further confirming the fact that the nanoparticle was FCC Ag. Apparently, there were certain interface orientation relationships between the ligaments and the $\mathrm{Ag}$ atoms (Fig. 9b).

\section{Ligament coarsening and corrosion mechanism}

Fig. 10 shows the mean diameter of the ligament as a function of time, and the fitting shows a general linear relationship. Thus, the following relationship could be predicted between the diameter of the ligament $(d)$ and dealloying time $(t):^{35}$

$$
d^{n}=K t D_{\mathrm{s}}
$$

here, $K$ is a constant, $D_{\mathrm{s}}$ is the surface diffusivity at a certain temperature and $n$ is the coarsening exponent of the ligaments. By logarithmic transformation, the equation could be expressed as follows:

$$
n \ln d=\ln \left(K D_{\mathrm{s}}\right)+\ln t
$$

Eqn (3) shows a relationship between $d$ and $t$, i.e., $d \propto t^{1 / n}$. Furthermore, the slope of the fitting linear curve is equal to $1 / n$. However, there is not a definite relationship between the 

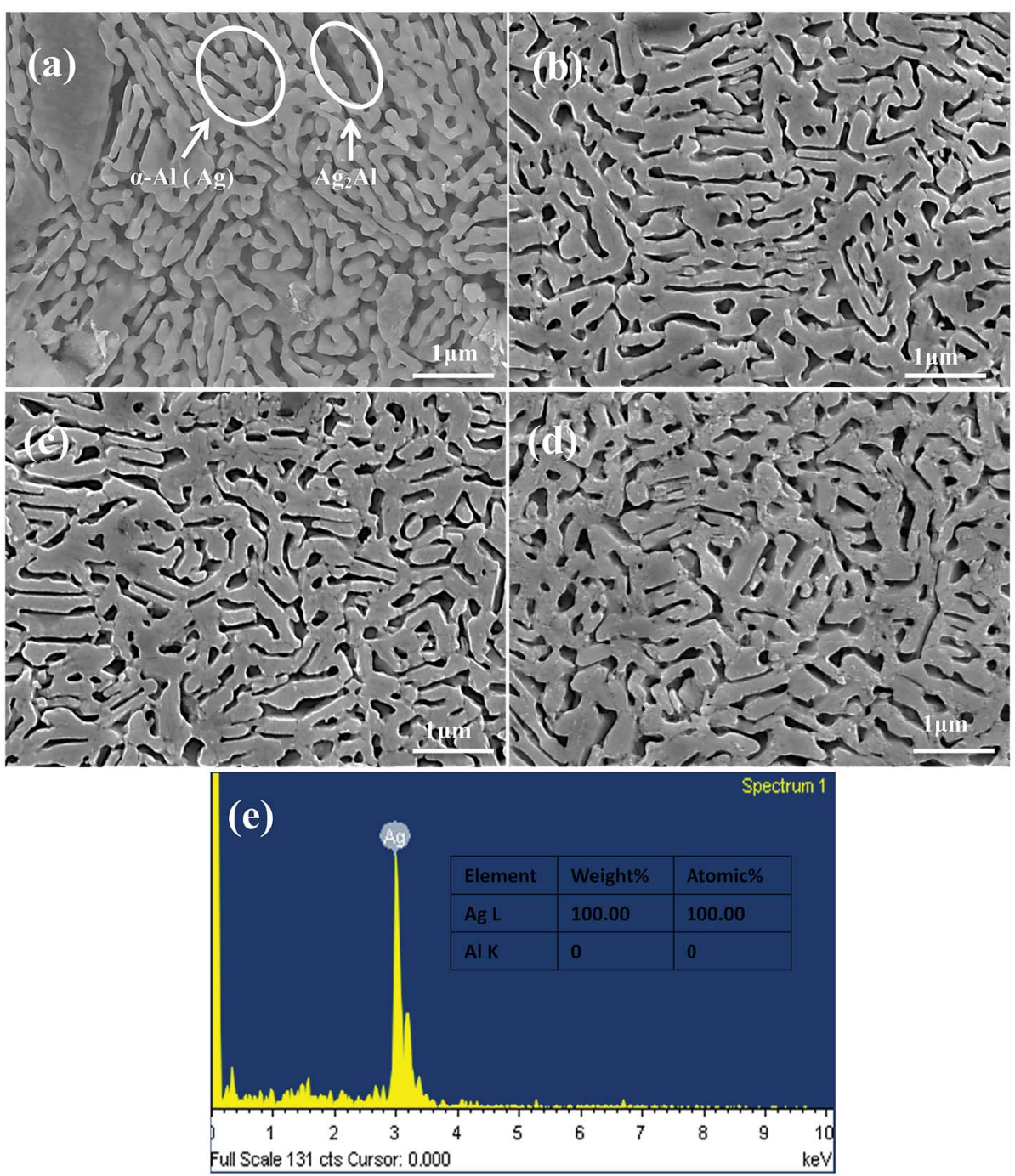

Fig. 7 SEM micrographs of the $\mathrm{Ag}_{40} \mathrm{Al}_{60}$ samples (plan view) under the dealloyed conditions for different periods of time: (a) 5 min, (b) 10 min, (c) $20 \mathrm{~min}$, and (d) $30 \mathrm{~min}$; (e) EDS pattern of $\mathrm{Ag}_{40} \mathrm{Al}_{60}$ sample dealloyed for $30 \mathrm{~min}$.

diameter of ligament $(d)$ and dealloying time $(t)$. The time dependence of the ligament coarsening is susceptible to many factors; for example, the ligament diameter exhibits a time dependence $d \propto t^{0.13} \approx t^{1 / 8}$ when dealloying ${ }^{36}$ and $d \propto t^{1 / 5}$ when sintering. ${ }^{37}$ The slope of the fitting linear curve (shown in Fig. 10) obtained from the $\mathrm{Ag}_{35} \mathrm{Al}_{65}\left(d \propto t^{0.49 \pm 0.04}\right)$ alloy is steeper than those obtained from the $\mathrm{Ag}_{30} \mathrm{Al}_{70}\left(d \propto t^{0.21 \pm 0.09}\right)$ and $\mathrm{Ag}_{40} \mathrm{Al}_{60}\left(d \propto t^{0.13 \pm 0.04}\right)$ alloys, suggesting that the rate of
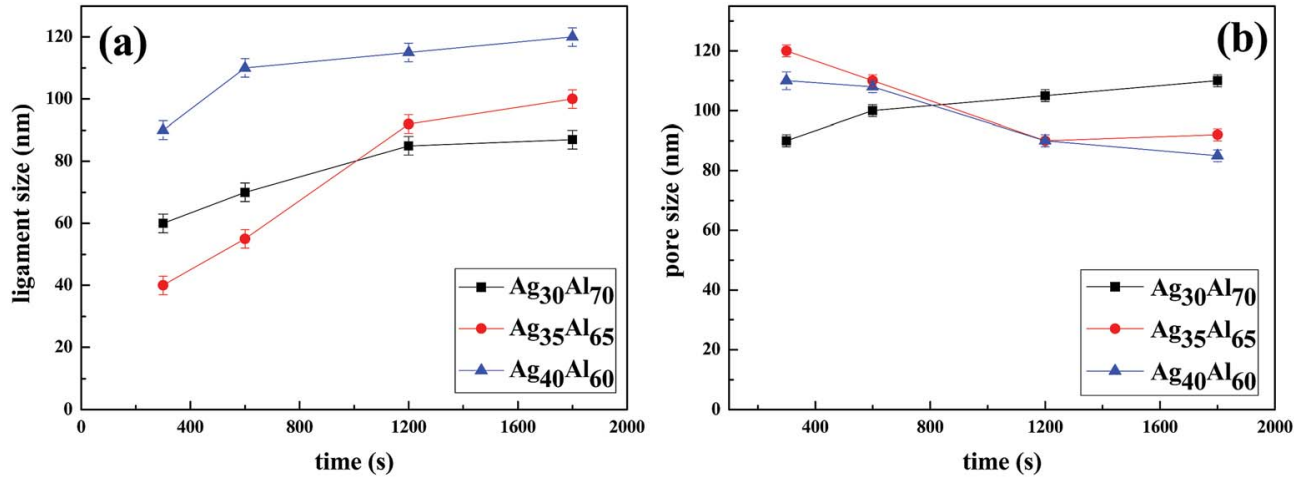

Fig. 8 Statistics of ligament size (a) and pore size (b) with the increasing dealloying time in different alloy samples. 

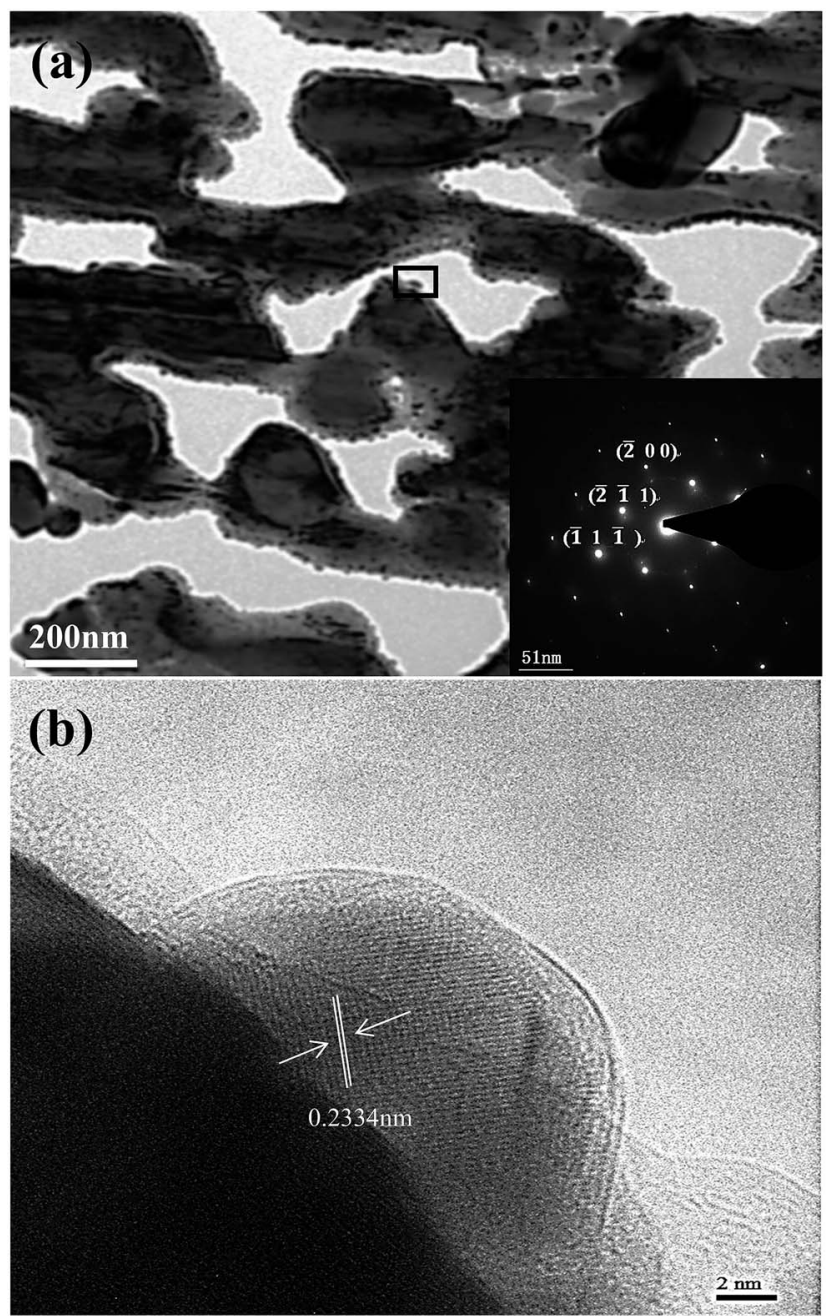

Fig. 9 (a) TEM bright-field image with SAED pattern inset for $\mathrm{Ag}_{35} \mathrm{Al}_{65}$ ribbons dealloyed for $30 \mathrm{~min}$; (b) selected areas (marked by rectangles in (a)) magnified HRTEM bright-field image.

ligament coarsening of $\mathrm{Ag}_{35} \mathrm{Al}_{65}$ is faster than those of the other two alloys.

The slopes $(0.21 \pm 0.04,0.49 \pm 0.09$ and $0.13 \pm 0.04)$ of the fitting lines for different compositions implied a variable coarsening mechanism at different conditions. Therefore, it is reasonable to assume that $\mathrm{Ag}$ content and the phase distribution in the precursor alloy were possible reasons for such results.

Referring to the binary Ag-Al diagram, ${ }^{31}$ we discovered that prior to the formation of the $\alpha-\mathrm{Al}(\mathrm{Ag}) / \gamma-\mathrm{Ag}_{2} \mathrm{Al}$ eutectic structure, the primary $\alpha-\mathrm{Al}(\mathrm{Ag})$ phase first precipitated during rapid solidification of the $\mathrm{Ag}_{30} \mathrm{Al}_{70}$ and $\mathrm{Ag}_{35} \mathrm{Al}_{65}$ alloys, whereas the primary $\gamma-\mathrm{Ag}_{2} \mathrm{Al}$ phase precipitated in preference to the $\alpha-\mathrm{Al}(\mathrm{Ag})$ phase during rapid solidification of the $\mathrm{Ag}_{40} \mathrm{Al}_{60}$ alloy. Therefore, large differences in the microstructures and morphologies of $\mathrm{Ag}_{30} \mathrm{Al}_{70}, \mathrm{Ag}_{35} \mathrm{Al}_{65}$ and $\mathrm{Ag}_{40} \mathrm{Al}_{60}$ initial alloys appeared. ${ }^{19,23}$ The observation from Fig. 2(a), (c) and (d) confirmed this prediction. Thus, these differences were mainly determined by the formation and distribution of the two phases $\left[\alpha-\mathrm{Al}(\mathrm{Ag})\right.$ and $\left.\gamma-\mathrm{Ag}_{2} \mathrm{Al}\right]$. By comparing the microstructures of $\mathrm{Ag}_{30} \mathrm{Al}_{70}, \mathrm{Ag}_{35} \mathrm{Al}_{65}$ and
$\mathrm{Ag}_{40} \mathrm{Al}_{60}$ during the dealloying process shown in Fig. 5-7, we found that the morphology of initial alloys and distribution of $\alpha-\mathrm{Al}(\mathrm{Ag})$ and $\gamma-\mathrm{Ag}_{2} \mathrm{Al}$ could influence the nanoporous structures significantly. However, there were some differences in the alloy solidification and nanoporous structure between our report and a former research. ${ }^{18}$ The reason may be that the experimental conditions and dealloying parameters presented in our research were different from those presented in the former research.

According to a new model of halo formation in directional solidification proposed by Nave, ${ }^{32}$ for $\mathrm{Ag}_{40} \mathrm{Al}_{60}$, the nucleation and growth of the eutectic structure directly occurred from the primary phase $\gamma-\mathrm{Ag}_{2} \mathrm{Al}$. However, for the $\mathrm{Ag}_{30} \mathrm{Al}_{70}$ and $\mathrm{Ag}_{35} \mathrm{Al}_{65}$ alloys, when the temperature rapidly decreased (the undercooling for nucleation was significant), a halo phase $\gamma-\mathrm{Ag}_{2} \mathrm{Al}$ was generated from the primary phase $\alpha-\mathrm{Al}(\mathrm{Ag})$, and it developed around the $\alpha-\mathrm{Al}(\mathrm{Ag})$ phase before the eutectic formation occurred. Therefore, the $\alpha-\mathrm{Al}(\mathrm{Ag})$ phase was enveloped by the $\gamma$ $\mathrm{Ag}_{2} \mathrm{Al}$ phase (Fig. 6a). There would be more grain boundaries (or phase boundaries) in this kind of alloy so that the intergranular corrosion would be facilitated, and this distinct phase distribution could improve the dealloying ability.

Fig. 11(a) shows the HRTEM image of a whole cross section incised via FIB from the initial $\mathrm{Ag}_{35} \mathrm{Al}_{75}$ alloy sample and reveals a clear morphology of the internal structure. Fig. 11(b) and (c) depict the HRTEM photographs of the areas selected from Fig. 11(a), marked by red and blue rectangles, respectively. We can clearly the observe grain boundaries distributed in the alloy interior from Fig. 11(a). Fig. 11(d) is the corresponding dark field TEM (DF-TEM) image of Fig. 11(c). There are two spots (EDS-1 and EDS-2) located in Fig. 11(b) and (c) which are detected by EDX, and the EDS results are shown in Fig. 11(e) and (f), respectively. According to the EDS patterns, the bright and dark regions, corresponding to $\mathrm{Ag}_{2} \mathrm{Al}$ and $\alpha-\mathrm{Al}(\mathrm{Ag})$, respectively, show a distinct distribution of different phases.

As can be observed from Fig. 5 and 6 , the intergranular corrosion corresponding to the etching at the grain boundary (phase boundary) occurred at the initial stage of the dealloying process for the $\mathrm{Ag}_{30} \mathrm{Al}_{70}$ and $\mathrm{Ag}_{35} \mathrm{Al}_{65}$ alloys, resulting in the appearance of deep channels (or cracks) at the phase boundary. Since the phase boundary or grain boundary was less stable than the grains inside, the preferential etching of $\mathrm{Al}$ occurred from the phase boundaries. Thus, as is shown in Fig. 6(a), the microstructure dealloyed from the $\alpha$ - $\mathrm{Al}(\mathrm{Ag})$ phase exhibited a 3D bi-continuous ligament/pore structure. Additionally, the structure dealloyed from $\gamma-\mathrm{Ag}_{2} \mathrm{Al}$ was a pore-wall structure. This phenomenon was beneficial for the dissolution of $\mathrm{Al}$ and for increasing the dealloying rate, due to which the dealloying rate of $\mathrm{Ag}_{40} \mathrm{Al}_{60}$ became relatively slow. However, compared with the more active phase $\alpha-\mathrm{Al}(\mathrm{Ag})$, which could be easily dealloyed in the electrolyte, the inert phase $\gamma-\mathrm{Ag}_{2} \mathrm{Al}$ was less prone to directly react with the $\mathrm{HCl}$ solution. As a result, the ligaments of asdealloyed $\mathrm{Ag}_{40} \mathrm{Al}_{60}$ were seriously coarsened (Fig. 7d). In addition, due to the synthesised effect of $\alpha-\mathrm{Al}(\mathrm{Ag})$ and $\gamma-\mathrm{Ag}_{2} \mathrm{Al}$ phases, $\mathrm{Ag}_{35} \mathrm{Al}_{65}$ (eutectic composition) exhibited a homogeneous ligament/pore structure, whereas the microstructures of $\mathrm{Ag}_{30} \mathrm{Al}_{70}$ (hypoeutectic composition) and $\mathrm{Ag}_{40} \mathrm{Al}_{60}$ (hypereutectic composition) exhibited inhomogeneous thinning and 

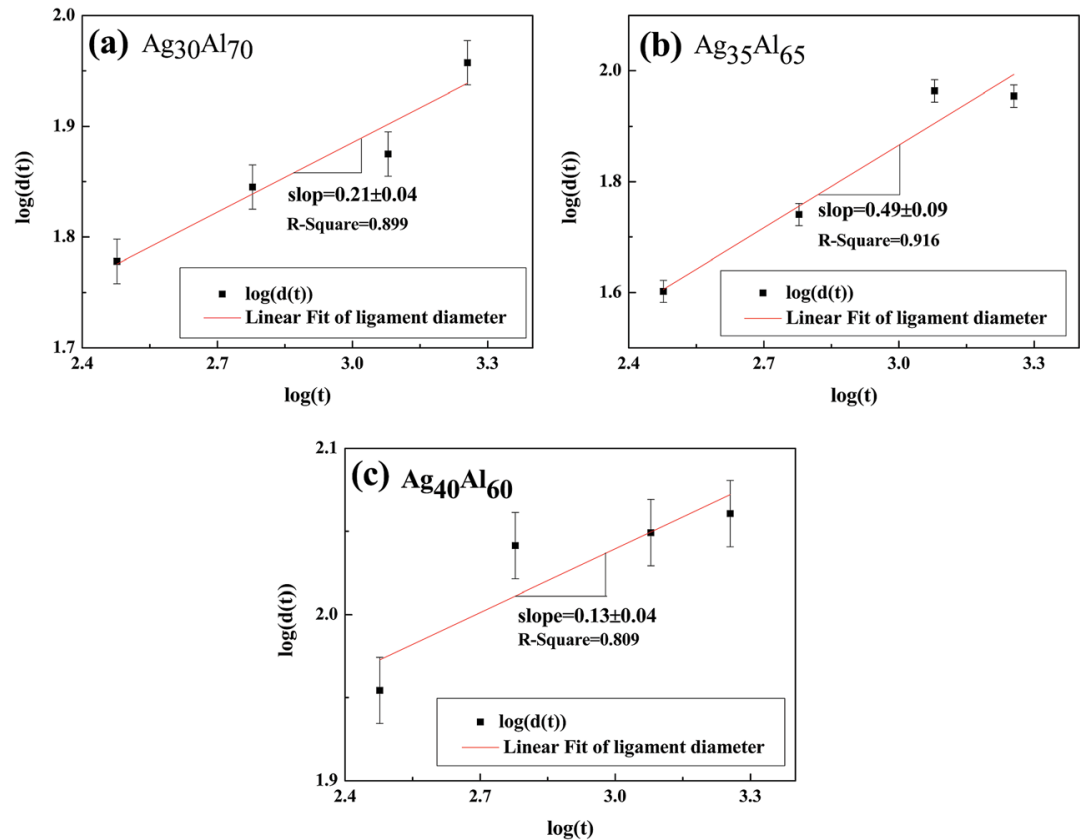

Fig. 10 Log-log plot of ligament diameter versus dealloying time for samples.

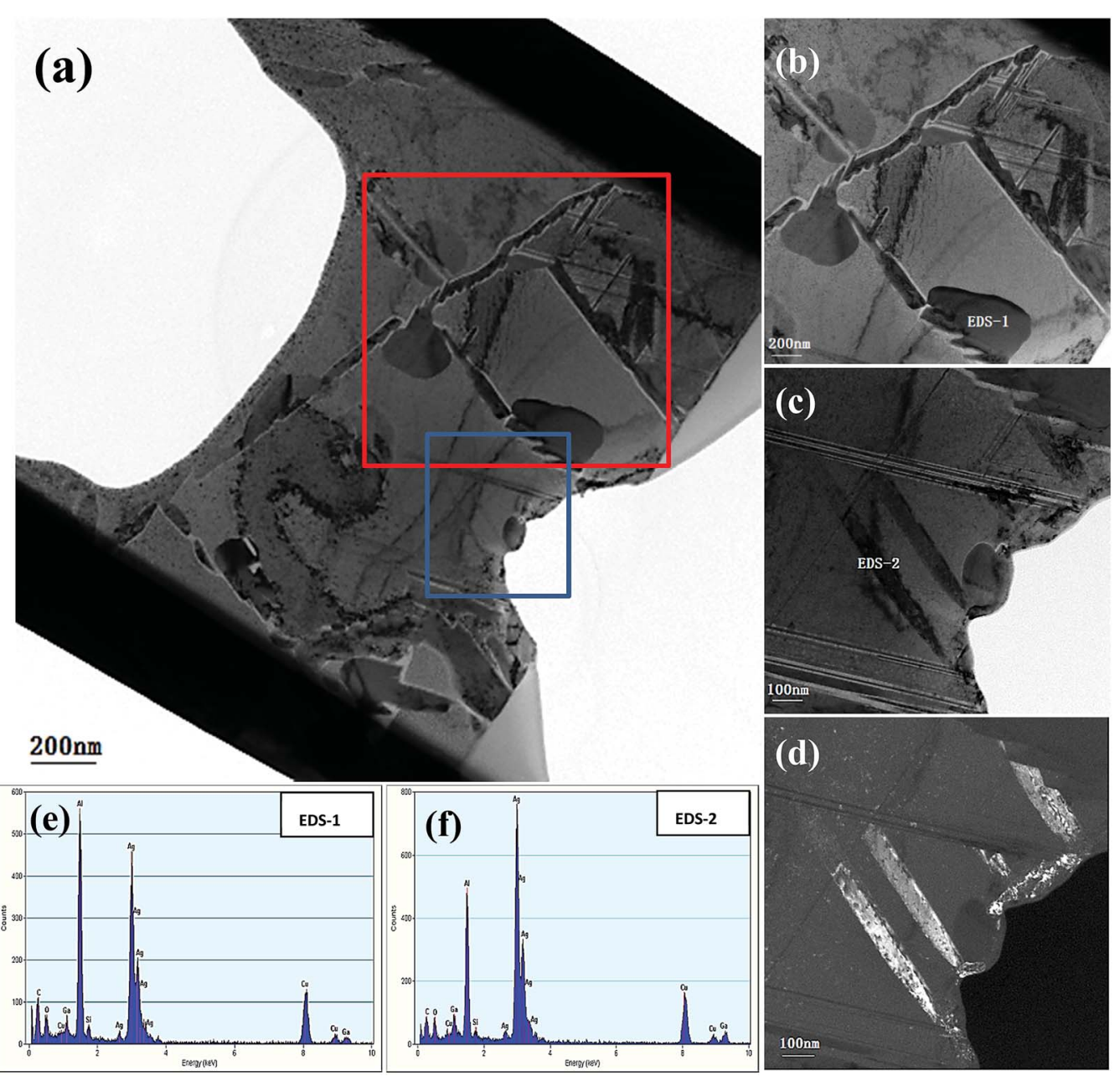

Fig. $11(\mathrm{a}-\mathrm{c})$ HRTEM images of a cross section incised via FIB and corresponding DF-TEM (d) and EDS (e, f) results of the Ag ${ }_{35} \mathrm{Al}_{65}$ initial alloy. 
coarsening of ligaments, respectively. This result confirmed that the synergetic dealloying of $\alpha-\mathrm{Al}(\mathrm{Ag})$ and $\gamma-\mathrm{Ag}_{2} \mathrm{Al}$ in the twophase $\mathrm{Ag}-\mathrm{Al}$ alloys was conducive to the formation of NPS with a homogeneous porous structure. ${ }^{19}$

\section{Conclusions}

(1) In summary, the composition of precursor alloys significantly affected the dealloying process and the formation of NPS. The size of the ligament in the as-dealloyed samples became larger with the increase in $\mathrm{Ag}$ content in the precursor alloy.

(2) Due to the variation of $\mathrm{Ag}$ content, the morphology in each precursor alloy was different. For the $\mathrm{Ag}_{30} \mathrm{Al}_{70}$ and $\mathrm{Ag}_{35} \mathrm{Al}_{65}$ alloys, when the temperature rapidly decreased (the undercooling for nucleation was significant), a halo phase $\gamma-\mathrm{Ag}_{2} \mathrm{Al}$ was generated from the primary phase $\alpha-\mathrm{Al}(\mathrm{Ag})$, and it developed around the $\alpha-\mathrm{Al}(\mathrm{Ag})$ phase before the eutectic formation occurred. In addition, for the $\mathrm{Ag}_{40} \mathrm{Al}_{60}$ alloy, the nucleation and growth of the eutectic structure directly occurred from the primary phase $\gamma-\mathrm{Ag}_{2} \mathrm{Al}$ with no halos.

(3) The formation of the halo phase accelerated the ligament coarsening rate because it provided more phase boundaries. With the synthesised effect of $\alpha-\mathrm{Al}(\mathrm{Ag})$ phase and $\gamma-\mathrm{Ag}_{2} \mathrm{Al}$ phase, $\mathrm{Ag}_{35} \mathrm{Al}_{65}$ (eutectic composition) exhibited a homogeneous ligament/pore structure, whereas the microstructures of $\mathrm{Ag}_{30} \mathrm{Al}_{70}$ (hypoeutectic composition) and $\mathrm{Ag}_{40} \mathrm{Al}_{60}$ (hypereutectic composition) with thinning and coarsening ligaments, respectively, exhibited inhomogeneous structures.

\section{Conflicts of interest}

There are no conflicts to declare.

\section{Acknowledgements}

The authors gratefully acknowledge the sponsorship from the National Natural Science Foundation of China, under the project No. 51574147 and Liaoning Provincial Natural Science Foundation of China, under the project No. 201602474.

\section{References}

1 Y. Ding and M. W. Chen, MRS Bull., 2009, 34, 569-576.

2 K. Wongravee, H. Gatemala and C. Thammacharoen, RSC Adv., 2014, 5, 1391-1397.

3 Z. Zhang, C. Zhang and J. Sun, RSC Adv., 2012, 2, 4481-4489.

4 H. J. Qiu, J. L. Kang and P. Liu, J. Power Sources, 2014, 247, 896-905.

5 R. Mao, S. H. Liang, X. H. Wang, Q. Yang and B. B. Han, Corros. Sci., 2012, 60, 231-237.

6 J. Erlebacher and K. Sieradzki, Scr. Mater., 2003, 49, 991-996.

7 R. C. Newman, S. G. Corcoran, J. Erlebacher, M. J. Aziz and K. Sieradzki, MRS Bull., 1999, 24, 24-28.

8 J. Erlebacher, M. J. Aziz, A. Karma, N. Dimitrov and K. Sieradzki, Nature, 2001, 410, 450-453.
9 H. O. Lee, E. M. Kim and H. Yu, Nanotechnology, 2009, 20, 325604.

10 K. P. Johnston and P. S. Shah, J. Mater. Sci., 2004, 303, 482483.

11 X. Wang, Z. Qi and C. Zhao, J. Phys. Chem., 2009, 113, 1313913150.

12 W. B. Liu, S. C. Zhang and N. Li, Microporous Mesoporous Mater., 2011, 138, 1-7.

13 Y. Ding, Y. J. Kim and J. Erlebacher, Adv. Mater., 2004, 16, 1897-1900.

14 D. V. Pugh, A. Dursun and S. G. Corcoran, J. Electrochem. Soc., 2005, 152, B455-B459.

15 C. X. Ji and P. C. Searson, J. Phys. Chem., 2003, 107, 44944499.

16 B. W. Jr Parks, J. D. Fritz and H. W. Pickering, Scr. Mater., 1989, 23, 951-956.

17 J. Snyder, P. Asanithi, A. B. Dalton and J. Erlebacher, Adv. Mater., 2008, 204, 4883-4886.

18 X. Wang, Z. Qi, C. Zhao, W. Wang and Z. Zhang, Phys. Chem., 2009, 113, 13139-13150.

19 Z. Qi, C. Zhao, X. Wang, J. Lin, W. Shao, Z. Zhang and X. Bian, J. Phys. Chem., 2009, 113, 6694-6698.

20 C. Zhao, Z. Qi, X. Wang and Z. Zhang, Corros. Sci., 2009, 51, 2120-2125.

21 Y. Wang and B. Wu, CrystEngComm, 2014, 16, 479-485.

22 F. Chen, X. Chen and L. Zou, Mater. Sci. Eng., A, 2016, 660, 241-250.

23 T. T. Song, Y. L. Gao and Z. H. Zhang, Corros. Sci., 2013, 68, 256-262.

24 L. Y. Chen, J. S. Yu and T. Fujita, Adv. Funct. Mater., 2009, 19, 1221-1226.

25 H. Qiu, Z. Zhang and X. Huang, ChemPhysChem, 2011, 12, 2118-2123.

26 T. Song, Y. Gao and Z. Zhang, CrystEngComm, 2011, 13, 7058-7067.

27 E. Detsi, Z. Vuković and S. Punzhin, CrystEngComm, 2012, 14, 5402-5406.

28 G. Li, X. Song and Z. Sun, Solid State Sci., 2011, 13, 13791384.

29 S. Parida, D. Kramer and C. A. Volkert, Phys. Rev. Lett., 2006, 97(3), 035504.

30 H. Rosner, S. Parida, D. Kramer, C. A. Volkert and J. Weissmuller, Adv. Eng. Mater., 2007, 9, 535-541.

31 A. J. McAlister, Bull. Alloy Phase Diagrams, 1987, 8526.

32 M. D. Nave, A. K. Dahle and D. H. Stjohn, Acta Mater., 2002, 50, 2837-2849.

33 W. R. Tyson and W. A. Miller, Surf. Sci., 1977, 62, 267-276.

34 L. H. Qian and M. W. Chen, Appl. Phys. Lett., 2007, 91, 597605.

35 G. Andreasen, J. Electrochem. Soc., 1996, 143, 29-36.

36 R. W. Balluffi, S. M. Allen and W. C. Carter, Kinetics of Materials, 2005.

37 Y. Sun and T. J. Balk, Metall. Mater. Trans. A, 2008, 39, 26562665. 